\title{
Role of central blood volume in hyperkinetic borderline hypertension ${ }^{1}$
}

\author{
Charles N. Ellis ${ }^{2}$ and Stevo Julius \\ From the Department of Internal Medicine (Hypertension Unit), \\ University of Michigan Medical School, Ann Arbor, Michigan, U.S.A.
}

Forty-nine patients with hyperkinetic borderline hypertension were compared to 64 healthy volunteers. Central blood volume in the patients was slightly raised. However, a detailed analysis of the results indicates that redistribution of the blood from the peripheral to central veins is not responsible for the rise in cardiac output and stroke volume in hyperkinetic patients. The results in a subgroup of patients who received an autonomic blockade with atropine and propranolol support the concept that the autonomic nervous system is responsible for the rise in cardiac output, heart rate, and stroke volume in these patients.

About 30 per cent of patients with borderline hypertension have increased resting cardiac output (Julius and Schork, 1971). The mechanism of this rise is not clearly understood. Increased sympathetic responsiveness (Frohlich, Tarazi, and Dustan, 1969) or sympathetic tone (Julius, Pascual, and London, 1971a), and increased catecholamines at rest (Kuschke, I96r) and after stress (Nestel, 1969) have been described; a decreased vagal inhibition in hyperkinetic borderline hypertension has also been described (Julius et al., 1971a). Whereas this indicates that the raised cardiac output in hyperkinetic borderline hypertension may stem from an abnormal autonomic cardiac control, other possibilities are also suggested. Thus, Guyton, in an elegant model of the development of hypertension (Guyton and Coleman, 1967), describes a primary rise in the cardiac output followed later by an autoregulatory increase of the peripheral resistance. Within the framework of this model, increased venous return due to expanded plasma volume initiates the increase in the cardiac output. While such a mechanism clearly applies to acute glomerulonephritis (DeFazio et al., 1959), liquorice ingestion (Koster and David, I968), and volume expanded anephric patients (Coleman et al., 1970), expanded plasma volume in essential hypertension has yet to be demonstrated. In fact there is strong evidence to the contrary; the plasma volume is decreased in the majority of Received 2 October 1972.

1 Supported by a grant from the American Heart Association, and Mr. Leo Fields.

${ }^{2}$ Charles N. Ellis is a trainee in the Cardiovascular Research Program, and in receipt of a NIH grant. patients with essential hypertension (Tarazi, Frohlich, and Dustan, 1968; Tibblin et al., 1966; Tarazi, Dustan, and Frohlich, 1969).

Theories about the mechanism of the rise in cardiac output in the early phase of hypertension should apply particularly well to borderline hypertension. These patients are at higher risk to develop later established essential hypertension; furthermore, this is the only form of hypertension of unknown origin in which a substantial proportion of cases has increased cardiac output (Julius and Schork, I97I). However, plasma volume in borderline hypertension is decreased (Julius et al., 197 Ib).

Increased venous return could nevertheless be responsible for the rise in cardiac output in borderline hypertension should these patients exhibit a redistribution of the blood in the capacitance system. It has been postulated that a shift of the blood from peripheral to central veins may be responsible for the increase in cardiac output in renovascular hypertension (Ulrych et al., 1969). The purpose of this paper is to evaluate whether a rise in cardiac output in hyperkinetic borderline hypertension could be explained by a similar redistribution of the blood in the capacitance system.

\section{Subjects and methods}

Sixty-four healthy paid volunteers who had three consecutive normotensive readings were compared to 49 patients with hyperkinetic borderline hypertension. All were male between 15 and 43 years of age. If a patient had at least one of three casual diastolic readings above and one below 90 within the last year, he was said to 
have borderline hypertension. All patients having a resting cardiac index one standard deviation above the normal mean were classified as hyperkinetic (i.e., above 3400 $\mathrm{ml} / \mathrm{min} / \mathrm{m}^{2}$ ). Every patient underwent a thorough clinical examination and none had any evidence of secondary hypertension.

The examination involved taking medical history with special reference to features suggesting renal disease, phaeochromocytoma, hyperthyroidism, or renal trauma. During the physical examination, special care was given to rule out weak femoral pulses, abdominal bruits, goitre, exophthalmos, and fine tremor. None of the patients had a history or signs of heart failure; all had normal fundoscopic examinations. In 29 patients intravenous pyelogram and electrolytes were done, and were normal in all.

Both the patients and volunteers were aware that the procedure could bring them no possible benefit and were informed of the possible risk of the investigation. They all signed an informed consent form in which the details of the procedure were outlined. Safety aspects of the procedure were reviewed and approved by the institutional committee for use of human subjects in experimental purposes.

Cardiac output was measured by dye dilution technique (using indocyanine green), blood pressure was measured intra-arterially, and heart rate determined from electrocardiographic tracings. Arterial blood was withdrawn from the brachial artery. 'Central' blood volume was calculated by multiplication of cardiac output by mean transit time determined from the inscribed cardiac output curves. A PE 50 catheter was introduced percutaneously into the antecubital vein and advanced by flotation to a predetermined length, to reach a central vein, based on external assessment of the distance from the cubital fossa to the top of the shoulder and then in a curved fashion to the midsternum. The central venous pressure was monitored and the appearance of characteristic intrathoracic pressures was used as assurance that the catheter did not curl up in the peripheral vein or float in the neck veins. In 8 patients and 15 controls (20\% of all subjects) this was not done, but the central blood volume values in these cases did not differ from the rest of the group. The mean transit time was corrected for the dead space in the withdrawal system and for the rate of withdrawal (Dock et al., 196r).
A Gilford densitometer, a Statham P 23 DB strain gauge, and a Gilson polygraph were used as described in detail elsewhere (Julius et al., I967). Plasma volume was measured by Evans blue. Optical density in samples taken IO, 15, and 20 minutes after the injection was extrapolated to zero time.

Resting measurements Io minutes after all catheters were placed were taken in all cases. Thereafter, in a subgroup of 31 control subjects and $I_{3}$ patients, an intravenous injection of propranolol $(0.2 \mathrm{mg} / \mathrm{kg})$ was administered over four minutes. Haemodynamic parameters were determined again 7 minutes after the injection. Immediately after this, an injection of $0.04 \mathrm{mg} / \mathrm{kg}$ of atropine sulphate intravenously was given over two minutes. Seven minutes later a repeated set of measurements was taken. In our previous investigation (Julius et al., 1971a), we concurred with Jose and Taylor (1969) that such a regimen substantially reduced physiological autonomic nervous influences on the heart.

The Student t-test was used to determine the significance of difference between the two groups.

\section{Results}

Table I shows the main haemodynamic resting findings. Hyperkinetic patients, who were selected for high resting cardiac indices, also showed increased heart rate, higher stroke volume, and somewhat raised central blood volume. Plasma volume, however, was similar in both groups of subjects.

Correlation coefficients of the central blood volume to cardiac output and stroke volume in both groups are given in Table 2. There was a weak correlation between the central blood volume and cardiac output in the control subjects, and no correlation in patients could be detected. Correlation of the central blood volume to cardiac output did not improve when the central blood volume was expressed as a fraction of total blood volume. On the other hand, correlation to stroke volume was significant both in controls and in patients.

Fig. I illustrates that at similar levels of central blood volume, patients with hyperkinetic borderline hypertension had a significantly higher stroke

TABLE I Mean and standard error of haemodynamic measurements at rest

\begin{tabular}{|c|c|c|c|c|c|}
\hline & Controls $(N)$ & & Patients $(N)$ & & Significance \\
\hline Heart rate (beats/min) & $64 \cdot 5 \pm I \cdot 0$ & (64) & $78 \cdot 5 \pm \mathrm{I} \cdot 8$ & (49) & 0.0001 \\
\hline Systolic blood pressure (mmHg) & $113 \cdot 0 \pm 1 \cdot 5$ & (64) & $136 \cdot 1 \pm 2 \cdot 1$ & (49) & 0.0001 \\
\hline Diastolic blood pressure (mmHg) & $64 \cdot 4 \pm I \cdot I$ & (64) & $76 \cdot 1 \pm I \cdot 4$ & (49) & $0.000 \mathrm{I}$ \\
\hline Mean blood pressure (mmHg) & $80 \cdot 6 \pm I \cdot 2$ & (64) & $96 \cdot 1 \pm I \cdot 5$ & (49) & 0.0001 \\
\hline Cardiac output $(\mathrm{ml} / \mathrm{min})$ & $5910 \pm 120$ & (64) & $8610 \pm 230$ & (49) & 0.0001 \\
\hline Cardiac index $\left(\mathrm{ml} / \mathrm{min} / \mathrm{m}^{2}\right)$ & $3020 \pm 50$ & (64) & $4240 \pm 100$ & (49) & 0.0001 \\
\hline Stroke volume (ml/beat) & $92 \cdot 8 \pm 2 \cdot 1$ & (64) & $\operatorname{lin} \cdot 7 \pm 3 \cdot 3$ & (49) & 0.0001 \\
\hline Central blood volume (ml) & $1610 \pm 40$ & $(64)$ & $1760 \pm 70$ & (49) & 0.06 \\
\hline Plasma volume (ml) & $3350 \pm 80$ & $(42)$ & $3202 \pm 90$ & (22) & NS \\
\hline
\end{tabular}


volume. Means of subject and patient values within defined intervals of central blood volume have been used for graphical presentation. Analysis of variance of the regression equation of the two groups verified that the two curves were significantly different $(\mathrm{P}<0.001)$.

TABLE 2 Correlation coefficients ( $r$ ) with central blood volume

\begin{tabular}{lll}
\hline & Controls $N=64$ & Patients $N=49$ \\
\hline Cardiac output & $\mathrm{r}=0.385 \mathrm{P}<0.002$ & $\mathrm{r}=0.226 \mathrm{NS}$ \\
Stroke volume & $\mathrm{r}=0.520 \mathrm{P}<0.000 \mathrm{I}$ & $\mathrm{r}=0.464 \mathrm{P}<0.00 \mathrm{I}$
\end{tabular}

The role of the central blood volume was further investigated in a subgroup of patients and control subjects in whom physiological autonomic control of the heart was abolished with injection of propranolol and atropine. Table 3 shows the initial values and values after autonomic blockade of the heart. Initially, hyperkinetic patients had similar central blood volume but higher cardiac output and stroke volume. After the blockade, the difference in cardiac output and stroke volume became insignificant but the central blood volumes remained similar in both groups. This experiment is further illustrated in Fig. 2. After the blockade, both groups had similar decreases of the central blood volumes. However, while control subjects exhibited a significant increase, patients showed a decrease of the cardiac output.

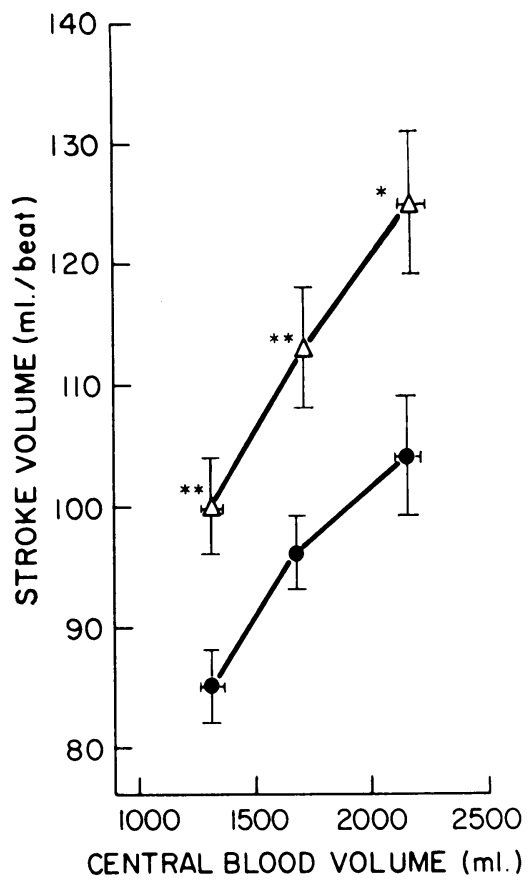

FIG. I Relation of stroke volume to central blood volume. The curves were constructed to represent means and standard errors of central blood volume and stroke volume for discrete intervals of central blood volume. (The first point, therefore, describes the values for all cases whose central blood volume fell between Iooo and I $500 \mathrm{ml}$.) Asterisks denote significance of difference of stroke volume from control subjects by Student t-test (*, $\left.P<0.05 ;{ }^{* *}, P<0.01\right) . \quad=$ control subjects; $\Delta$, hyperkinetic borderline hypertensives.

TABLE 3 Mean and standard error at rest and after intravenous injection of propranolol $(0.2 \mathrm{mg} / \mathrm{kg})$ and atropine sulphate $(0.04 \mathrm{mg} / \mathrm{kg})$

\begin{tabular}{|c|c|c|c|c|}
\hline & & Controls $N=3 I$ & Patients $N=13$ & Significance \\
\hline Heart rate (beats/min) & $\begin{array}{l}\text { Before } \\
\text { After }\end{array}$ & $\begin{array}{r}63 \cdot 9 \pm I \cdot 6 \\
I O I \cdot I \pm 2 \cdot 0\end{array}$ & $\begin{array}{l}74 \cdot 8 \pm 2 \cdot 9 \\
97 \cdot 4 \pm 2 \cdot 3\end{array}$ & $\begin{array}{l}\mathrm{P}<0.001 \\
\text { NS }\end{array}$ \\
\hline Cardiac output (ml/min) & $\begin{array}{l}\text { Before } \\
\text { After }\end{array}$ & $\begin{array}{l}5920 \pm 170 \\
6780 \pm 300\end{array}$ & $\begin{array}{l}8050 \pm 460 \\
7290 \pm 210\end{array}$ & $\begin{array}{l}\mathrm{P}<0.0001 \\
\mathrm{NS}\end{array}$ \\
\hline Cardiac index $\left(\mathrm{ml} / \mathrm{min} / \mathrm{m}^{2}\right)$ & $\begin{array}{l}\text { Before } \\
\text { After }\end{array}$ & $\begin{array}{l}2980 \pm 70 \\
3410 \pm 130\end{array}$ & $\begin{array}{l}4085 \pm 230 \\
3710 \pm 120\end{array}$ & $\begin{array}{l}P<0.0001 \\
N S\end{array}$ \\
\hline Stroke volume (ml/beat) & $\begin{array}{l}\text { Before } \\
\text { After }\end{array}$ & $\begin{array}{l}94 \cdot 0 \pm 3 \cdot 2 \\
67 \cdot 4 \pm 3 \cdot 0\end{array}$ & $\begin{array}{r}108 \cdot 3 \pm 5 \cdot 2 \\
75 \cdot 3 \pm 2 \cdot 7\end{array}$ & $\begin{array}{l}P<0.03 \\
N S\end{array}$ \\
\hline Central blood volume (ml) & $\begin{array}{l}\text { Before } \\
\text { After }\end{array}$ & $\begin{array}{l}1560 \pm 70 \\
1400 \pm 70\end{array}$ & $\begin{array}{l}1640 \pm 120 \\
1450 \pm 90\end{array}$ & $\begin{array}{l}\text { NS } \\
\text { NS }\end{array}$ \\
\hline
\end{tabular}




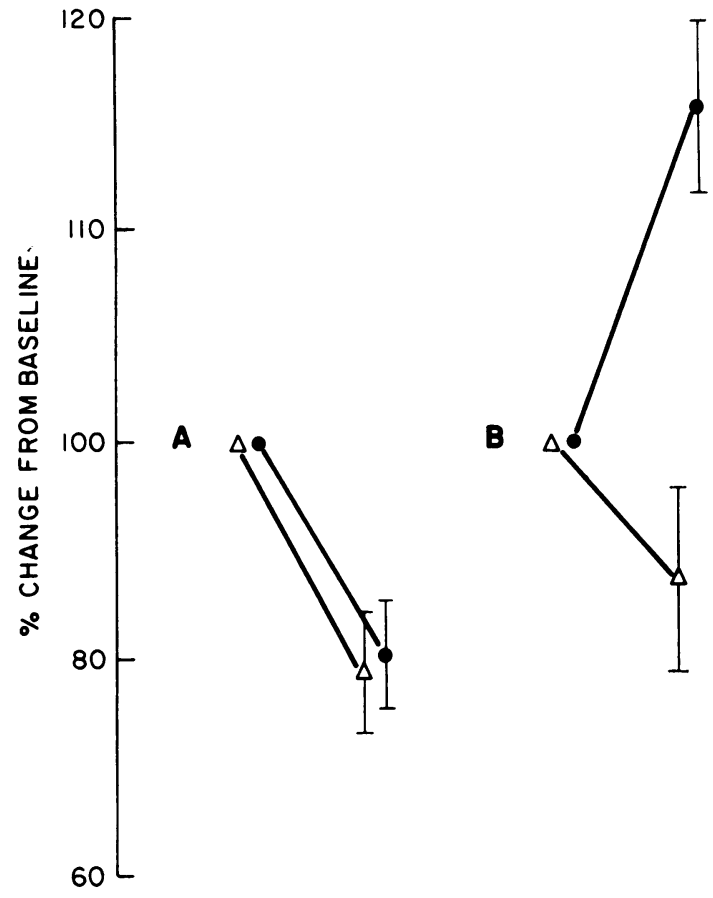

FIG. 2 Percentage change from rest to after propranolol and atropine: $(A)$ central blood volume; $(B)$ cardiac output. $A$ and $B$ represent changes that occurred during the same experiment and at the same time. 0 , control subjects; $\Delta$, hyperkinetic borderline hypertensives.

\section{Discussion}

\section{Methodological considerations}

Measures to secure that catheters were placed at the level of central veins were described in the method section. Though absence of fluoroscopic facilities introduces a certain lack of precision, it is reassuring to find that our values are comparable to other published data. Thus, McIntosh et al. (196I) advanced their dye catheter into the right atrium and sampled from the brachial artery; their mean central blood volume was equal to the mean of our control subjects. Similarly, when the central blood volumes in normotensive volunteers in Ulrych et al. (1969) are corrected for delay in the withdrawal system, their results are identical to ours. As expected, our control values are lower $\left(200 \mathrm{ml} / \mathrm{m}^{2}\right)$ than those of Marshall and Shepherd (196I) whose dye catheter lay at the lower end of the superior vena cava and who sampled at a more distal site in the radial artery.

Other evidence that values of central blood volume as measured in this study are meaningful stems from the finding that a strong correlation exists between central blood volume and stroke volume. Such a physiological relation was consistently found by other investigators (Levinson, Frank, and Hellems, 1964; Levinson, Pacifico, and Frank, 1966; Ulrych et al., 1969; Milnor, Jose, and McGaff, 1960).

The sampling site in the brachial artery poses another methodological problem. It has been shown that the velocity of arterial flow may influence central blood volume readings. Thus, reactive hyperaemia in the arm results in underestimation (Marshall and Shepherd, 196r; McIntosh et al., r96r), whereas redistribution of the flow to lower extremities produces higher central blood volume readings (McIntosh et al., 196I). However, this distortion was caused by big changes in flow, far beyond anything expected in resting subjects. Thus, in the hyperaemia experiment, a tenfold increase of baseline flow was applied to demonstrate the distortion of central blood volume results. Recent measurements by Amery, Bossaert, and Verstraete (1969) confirmed Brod's suggestion (Brod, I960) that patients with hypertension have increased muscle flow. However, this increase is only one-fifth above the values in normal subjects. Therefore it is unlikely that increased flow could cause serious distortion of central blood volume values in our patients.

\section{Haemodynamic changes in hyperkinetic bor- derline hypertension}

Time and again we are impressed with the reproducibility of abnormal haemodynamic findings in borderline hypertension. Thus our subjects were selected for occasional blood pressure increase in the past, and, as before (Sannerstedt, Julius, and Conway, 1970) during their laboratory investigations which occurred weeks to months after the transient pressure rise, they showed blood pressure readings which could be considered 'normal' ( $\mathrm{I} 36 \cdot \mathrm{I} \pm 2 \cdot \mathrm{I} / 76 \cdot \mathrm{I} \pm \mathrm{I} \cdot 4 \mathrm{mmHg}$ ). However, these pressures were significantly higher than in controls and were accompanied'by increased heart rate, increased stroke volume, and, of course, by definition, increased cardiac output. Such consistent and multiple aberrations from the normal, which are quite reproducible (Julius and Conway, 1968; Julius et al., I97I $\mathrm{b}, \mathrm{c}$ ), certainly call for investigation. In this discussion, we shall evaluate some possible causes for raised cardiac output.

It has been suggested (Finkielman, Worcel, and Agrest, I965) on theoretical grounds that raised cardiac output in labile hypertension may be caused by 'central' displacement of the blood in the capacitance system. Recently Ulrych et al. (1969) suggested that in renovascular hypertension there was a 
relation between the central blood volume and increased cardiac output. This finding, however, may be spurious because the correlation was computed in a heterogeneous group consisting of control subjects, patients with essential, and patients with renovascular hypertension. In the subgroup of renovascular hypertension in their study, in fact, there was no correlation between central blood volume and cardiac output. Other investigators could not find a correlation between cardiac output and central blood volume in normotensive subjects (Levinson et al., 1964, 1966; Dock et al., 1961), and in our control subjects there was only a weak correlation. In patients with hyperkinetic borderline hypertension in this study, there was no correlation between cardiac output and central blood volume. Thus, the increased cardiac output in these patients could not be explained by redistribution of blood to central veins.

Further evidence that the behaviour of cardiac output is not related to central blood volume may be seen in Fig. 2 where patients and control subjects after autonomic cardiac blockade exhibited a similar decrease of central blood volume, but the cardiac output increased in control subjects and, conversely, decreased in patients.

However, a cursory look at Table $I$ in this study indicates that the cardiac output in borderline hypertension was raised both due to increased heart rate and increased stroke volume. Since patients had somewhat higher central blood volume and since there is a strong relation between stroke volume and central blood volume, one could postulate that a central redistribution of the intravascular volume is responsible for the stroke volume component of the increased cardiac output. Our data do not support such a relation. Thus, in Fig. I, one can see that for each similar level of central blood volume, patients with hyperkinetic borderline hypertension have a significantly higher stroke volume. In other words, a different relation between the central blood volume and stroke volume exists in patients than exists in control subjects. Regression equations for patients $(\mathrm{SV}=7 \mathrm{I} \cdot 9+0.025 \mathrm{CBV})$ and controls $(\mathrm{SV}=50.9$ $+0.22 \mathrm{CBV}$ ) show similar slopes but the intercepts are significantly different $(\mathbf{P}<0.00 \mathrm{I})$. If the redistribution of the blood to central veins were responsible for the increased stroke volume, one would expect the patients to fall along a right-hand extension of the normal central blood volumestroke volume regression line.

If one assumes that distribution of the blood in central veins relates to cardiac venous filling, it follows that, for a similar degree of filling, patients with hyperkinetic borderline hypertension respond with a bigger stroke volume. The mechanism responsible for the increased stroke volume remains speculative, but our data indicate a strong neurogenic component. Thus, in the subgroup presented in Table 3, cardiac index, stroke volume, and heart rate were significantly raised at rest, but fell to a normal range after the autonomic blockade of the heart with propranolol and atropine. The 'normalization' of cardiac output which occurred after the blockade was not caused by shifts of the intravascular volume. Thus, after the blockade, both control subjects and patients had small and similar decreases in the central blood volume. It appears therefore that an intact direct autonomic control of the heart is essential for the maintenance of raised cardiac output in hyperkinetic borderline hypertension.

\section{Conclusions}

I) There is a correlation between stroke volume and central blood volume both in patients with hyperkinetic borderline hypertension and in control subjects.

2) Though both central blood volume and stroke volume were raised in the patients, the increase in the central blood volume did not appear to be responsible for the higher stroke volume.

3) Increases of cardiac output, heart rate, and stroke volume in patients were abolished after cardiac autonomic nervous blockade, though the blockade had little influence on the central blood volume. This is indicative of a strong neurogenic role in the maintenance of the increase of both components of cardiac output (heart rate and stroke volume).

\section{References}

Amery, A., Bossaert, H., and Verstraete, M. (1969). Muscle blood flow in normal and hypertensive subjects. American Heart Fournal, 78, $21 \mathrm{I}$.

Brod, J. (1960). Essential hypertension: haemodynamic observations with a bearing on its pathogenesis. Lancet, 2, 773 .

Coleman, T. G., Bower, J. D., Langford, H. G., and Guyton, A. C. (1970). Regulation of arterial pressure in the anephric state. Circulation, 42, 509.

DeFazio, V., Christensen, R. C., Regan, T. J., Baer, L. J., Morita, Y., and Hellems, H. K. (I959). Circulatory changes in acute glomerulonephritis. Circulation, 20, 190.

Dock, D. S., Kraus, W. L., McGuire, L. B., Hyland, J. W., Haynes, F. W., and Dexter, L. (1961). The pulmonary blood volume in man. Fournal of Clinical Investigation, 40, 317.

Finkielman, S., Worcel, M., and Agrest, A. (1965). Hemodynamic patterns in essential hypertension. Circulation, 31, 356.

Frohlich, E. D., Tarazi, R. C., and Dustan, H. P. (1969) Hyperdynamic $\beta$-adrenergic circulatory state: increased $\beta$-receptor responsiveness. Archives of Internal Medicine, 123, I.

Guyton, A. C., and Coleman, T. G. (1967). Long-term regulation of the circulation: interrelationships with body fluid volumes. In Physical Bases of Circulatory Transport: Regulation and Exchange, p. 179. Ed. by E. B. Reeve and A. C. Guyton. W. B. Saunders, Philadelphia. 
Jose, A. D., and Taylor, R. R. (1969). Autonomic blockade by propranolol and atropine to study intrinsic myocardial function in man. Fournal of Clinical Investigation, 48, 2019.

Julius, S., Amery, A., Whitlock, L. S., and Conway, J. (I967). Influence of age on the hemodynamic response to exercise. Circulation, 36, 222.

Julius, S., and Conway, J. (1968). Hemodynamic studies in patients with borderline blood pressure elevation. Circulation, 38, 282.

Julius, S., Pascual, A. V., and London, R. (1971a). Role of parasympathetic inhibition in the hyperkinetic type of borderline hypertension. Circulation, 44, 413.

Julius, S., Pascual, A. V., Reilly, K., and London, R. (I97Ib). Abnormalities of plasma volume in borderline hypertension. Archives of Internal Medicine, 127, 116.

Julius, S., Pascual, A. V., Sannerstedt, R., and Mitchell, C. (I97IC). Relationship between cardiac output and peripheral resistance in borderline hypertension. Circulation, 43, 382.

Julius, S., and Schork, M. A. (197I). Borderline hypertension - a critical review. Fournal of Chronic Diseases, 23, 723.

Koster, M., and David, G. K. (1968). Reversible severe hypertension due to licorice ingestion. New England fournal of Medicine, 278, 1381 .

Kuschke, H. J. (I96I). Untersuchungen über den Erregungszustand des sympathischen Nervensystems und des Nebennierenmarkes bei kardiovaskulären Erkrankungen. Archiv für Kreislaufforschung, 36, 104.

Levinson, G. E., Frank, M. J., and Hellems, H. K. (1964). The pulmonary vascular volume in man. Measurement from atrial dilution curves. American Heart fournal, 67 , 734.

Levinson, G. E., Pacifico, A. D., and Frank, M. J. (I966). Studies of cardiopulmonary blood volume: measurement of total cardiopulmonary blood volume in normal human subjects at rest and during exercise. Circulation, 33, 347.
McIntosh, H. D., Gleason, W. L., Miller, D. E., and Bacos, J. M. (196I). A major pitfall in the interpretation of 'central blood volume'. Circulation Research, 9, 1223.

Marshall, R. J., and Shepherd, J. T. (I96I). Interpretation of changes in 'central' blood volume and slope volume during exercise in man. Fournal of Clinical Investigation, 40, 375.

Milnor, W. R., Jose, A. D., and McGaff, C. J. (I960). Pulmonary vascular volume, resistance, and compliance in man. Circulation, 22, 130.

Nestel, P. J. (1969). Blood pressure and catecholamine excretion after mental stress in labile hypertension. Lancet, $\mathbf{I}$, 692.

Sannerstedt, R., Julius, S., and Conway, J. (1970). Hemodynamic responses to tilt and beta-adrenergic blockade in young patients with borderline hypertension. Circulation, 42, 1057.

Tarazi, R. C., Dustan, H. P., and Frohlich, E. D. (1969). Relation of plasma to interstitial fluid volume in essential hypertension. Circulation, 40, 357.

Tarazi, R. C., Frohlich, E. D., and Dustan, H. P. (1968) Plasma volume in men with essential hypertension. New England fournal of Medicine, 278, 762.

Tibblin, G.; Bergentz, S. E., Bjure, J., and Wilhelmsen, L. (1966). Hematocrit, plasma protein, plasma volume, and viscosity in early hypertensive disease. American Heart fournal, 72, 165 .

Ulrych, M., Frohlich, E. D., Tarazi, R. C., Dustan, H. P., and Page, I. H. (1969). Cardiac output and distribution of blood volume in central and peripheral circulations in hypertensive and normotensive man. British Heart fournal, 31, 570 .

Requests for reprints to Dr. Stevo Julius, Department of Internal Medicine (Hypertension Unit), University of Michigan Medical Center, Ann Arbor, Michigan 48ro4, U.S.A. 